\title{
TRÁFICO DE DROGAS E ENCARCERAMENTO
}

\section{DRUG TRAFFICKING AND INCARCERATION}

Millena Fernandes das chagas

Manoel Matias de Carvalho Neto

Lúcio Romero Marinho Pereira

RESUMO: O presente artigo tem por objetivo averiguar quais as consequências da política antidrogas e sua repercussão no meio prisional na Comarca de Mossoró/RN, para isso, compromete-se a analisar o perfil social e os atos inquisitivos e processuais constantes as ações penais que levaram indivíduos a serem condenados em decorrência da prática de crimes elencados na lei 11.343/2006. Para alcançar os objetivos, utilizou-se a pesquisa documental direta, tomando como fonte 88 (oitenta e oito) processos em fase de conhecimento e 77 (setenta e sete) em sede de Execução Penal de apenados condenados pela prática dos tipos da Lei n. ${ }^{\circ}$ 11.343/2006 que tramitam nas unidades judiciárias estaduais criminais da Comarca de Mossoró - RN, instaurados entre os anos de 2006 a 2019. Foram coletados e analisados dados sociais sendo filtrado por referenciais teóricos como Wacquant, Pavarini e outros doutrinadores das ciências jurídicas e sociais e utilizando-se de tais teorias: populismo punitivista, encarceramento em massa, Teoria do Etiquetamento social, eugenia social entre outras para traduzir cientificamente a realidade local.

Palavras-chaves: Política Antidrogas. Apenados. Processo Penal. Encarceramento em Massa.

ABSTRACT: The purpose of this article is to investigate the consequences of the anti-drug policy and its repercussion in the prison environment in the District of Mossoro / RN, for this, it undertakes to analyze the social profile and the inquisitive and procedural acts contained in the criminal actions that led individuals to be convicted as a result of the crimes listed in law 11.343 / 2006. To achieve a certain objective, direct documentary research was used, using as source 88 (eighty-eight) cases in the stage of knowledge and 77 (seventy-seven) in the area of Criminal Execution of convicted inmates for the practice of the types of Law 11.343 / 2006 that are being processed in the criminal state judicial units of the District of Mossoró - RN, established between the years 2006 to 2019. Social data were collected and analyzed, being filtered by theoretical references such as WACQUANT, PAVARINI and other legal and social sciences doctrines and using theories such as punitive populism, mass incarceration, Theory of social labeling, social eugenics among others to translate scientifically to local reality.

Keywords: Anti-Drug Policy. Jailed. Criminal proceedings. Mass Incarceration. 


\section{INTRODUÇÃO}

A ciência surge no contexto humano como uma necessidade de saber o porquê dos acontecimentos (LAKATOS; MARCONI, 2003), sendo uma forma de analisar e compreender o mundo através de um conjunto de métodos e técnicas. Bem por isso, gostaríamos de mencionar a importância da Pesquisa Cientifica dentro das Universidades, a qual, segundo Teixeira (2010), é a forma de conhecimento primordial para o alcance de uma educação de qualidade.

Nesse contexto, o presente artigo propõe discutir os dados obtidos através de uma pesquisa realizada nas Varas de Execução Penal da Comarca de Mossoró - RN, tendo em vista a dimensão dos efeitos da política antidrogas na conjuntura do sistema carcerário da Comarca em questão, o qual se encontra em uma realidade de superlotação, observando-se que, na sua maioria, o contingente carcerário é formado por pessoas que foram condenadas pela prática do crime de tráfico de drogas.

O uso de substâncias psicoativas sempre esteve presente na história da Humanidade, a qual “apresenta uma propensão singular a procurar substâncias psicotrópicas e, não raro, de persistir em seu uso, não obstante os seus inerentes riscos" (IVERSEN, 2012, p.17 apud ANDRADE, 2015, p.55). Com a força de setores moralistas da sociedade norte-americana, em uma escala crescente de proibicionismo, deflagrou-se a Guerra Contra as Drogas, consistindo em um conjunto de políticas públicas voltadas, em modalidade bélica, à eliminação da produção, distribuição e consumo de drogas proscritas. Tal política foi expandida para os países periféricos, utilizando as legislações penais e processuais penais internas como instrumentos de segurança pública.

Assim sendo, esses fatos culminaram no crescimento desordenado da população carcerária, uma vez que as edições da Lei de Drogas, especificamente a Lei ${ }^{\circ}$ 11.343/2006, enrijeceu o sistema com o aumento da pena mínima, estabelecendo uma margem discricionária para a tipificação da conduta delituosa. À vista disso, justifica-se a importância da presente pesquisa, ao passo que tais modificações legislativas de endurecimento, com grande desprendimento de recursos públicos, resultaram no crescimento do mercado internacional de substâncias ilícitas, com o amparo do crime organizado, bem como o aumento da população carcerária e de homicídios (ANDRADE, 2015) e, para além disso, contribuindo com a conversão do cidadão marginalizado em verdadeiros marginais.

Destarte, a pesquisa tem por objetivo averiguar quais as consequências da política antidrogas e sua repercussão no meio prisional na Comarca de Mossoró/RN, para isso, compromete-se a analisar o perfil social e os atos inquisitivos e processuais constantes as ações penais que levaram indivíduos a serem condenados em decorrência da prática de crimes elencados na Lei n. ${ }^{\circ} 11.343 / 2006$.

A metodológica deste artigo se baseia da pesquisa documental direta que, segundo Marconi e Lakatos (2008, p.188), “constitui-se, em geral, no levantamento de dados no próprio local onde os fenômenos ocorrem”. Além disso, explica os autores citados que a pesquisa se subdivide em pesquisa de campo e a de laboratório. No caso, optou-se, notadamente, pela pesquisa de campo, que é aquela na qual se busca colher 
dados com o fito de encontrar uma resposta para um problema levantado.

Por conseguinte, a pesquisa em apreço valeu-se preponderantemente da pesquisa quantitativoqualitativa, eis que dos dados numéricos catalogados exsurge a necessidade de uma análise aprofundada dos fenômenos sociais que os cercam. Nesse passo, com a finalidade precípua de observar o perfil sociodemográfico - e outras informações relacionadas aos processos - dos apenados, cumpriu-se a missão de analisar, detalhadamente, as informações constantes nos autos, indo desde o inquérito policial, perpassando pela denúncia, decisões interlocutórias, sentenças, acórdãos, até a fase executória da pena.

Neste norte, os pontos da pesquisa foram os seguintes: comarca de origem, magistrado sentenciante, capitulação do crime cometido, pena, regime carcerário, tipo e quantidade da droga apreendida no momento da prisão, antecedentes, reincidência, tipo da defesa no processo de conhecimento e execução, sexo, idade ao tempo do fato, local de residência, estado civil, escolaridade, existência de filhos, etnia, profissão e indícios de organização criminosa.

Todos os dados foram delimitados a partir das relações processuais e dados sociais obtidos em 88 (oitenta e oito) processos em fase de conhecimento e 77 (setenta e sete) em sede de Execução Penal de apenados condenados pela prática dos tipos da Lei n. ${ }^{\circ} 11.343 / 2006$ que tramitam nas unidades judiciárias estaduais criminais da Comarca de Mossoró - RN, instaurados entre os anos de 2006 a 2019. A quantidade de processos de conhecimento não é coincidente, haja vista que durante a pesquisa constatou-se apenados que possuíam mais de uma condenação por crimes de drogas, fato esse que justifica a existência dos 88 (oitenta e oito) processos de conhecimento. Ademais, devido a inconstância da presença das informações buscadas nos documentos analisados, em alguns tópicos, não foi possível a identificação em sua totalidade.

\section{O FENÔMENO DO ENCARCERAMENTO EM MASSA}

Durante a década de 1950 e o início dos anos 1960, propagou-se a Teoria do Etiquetamento social, o qual instituiu uma referência ao perfil do criminoso. Assim, segundo Raissa da Silva, esse novo modelo "foi chamado de paradigma da reação social, pois critica o antigo paradigma etiológico, que analisava o criminoso segundo suas características individuais. O novo paradigma tem por objeto de análise o sistema penal e o fenômeno de controle"1 (SILVA, 2015,p. 102).

A Teoria do Labelling Approach busca compreender a criminalidade indicando que o crime não ocorre, unicamente, por questões etiológicas, como era entendido nas teorias do positivista Cesare Lombroso em seu L'uommo delinquente, mas sim, pelas instâncias de controle que etiquetam e classificam as condutas

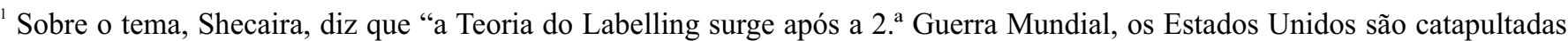
condição de grande potência mundial, estando em pleno desenvolvimento o Estado do Bem-Estar Social, o que acaba por mascarar as fissuras internas vividas na sociedade americana. A década de 60 é marcada no plano externo pela divisão mundial entre blocos: capitalista versus socialista, delimitando o cenário da chamada Guerra Fria. Já no plano interno, os norte-americanos se deparam com a luta das minorias negras por igualdade, a luta pelo fim da discriminação sexual, o engajamento dos movimentos estudantis na reivindicação pelos direitos civis" (SHECAIRA, Sérgio Salomão. Criminologia. São Paulo: Ed. RT, 2004. p. 371-374)
} 
como criminosas. Desse modo, remete-se uma conexão com a triagem do sistema penal e, por conseguinte, ao ciclo da criminalização, tendo em vista que nem todos os crimes são perseguidos pela sociedade e pelo Estado, punindo-se, assim, apenas uma parcela de delitos e indivíduos, estigmatizadas e condenadas ao mundo do crime. Nesse sentido, Eugenio Raúl Zaffaroni afirma que este fenômeno é "a catalogação dos criminosos que combinam com a imagem que corresponde à descrição fabricada, deixando de fora outros tipos de delinquentes"(ZAFFARONI, 1991).

Destarte, esse grupo selecionado forma o sistema carcerário brasileiro, que em números representam, de acordo com o Levantamento Nacional de Informações Penitenciárias - INFOPEN, 777.151 (setecentos e setenta e sete mil cento e cinquenta e uma) pessoas privadas de liberdade em todos os regimes, vale ressaltar, ainda, que do último semestre de 2018 para o primeiro de 2019 , houve um aumento de $3,89 \%$ do número de encarcerados (BRASIL, 2019). Assim, evidencia-se a superlotação do sistema, além de colocar em questão a efetividade do princípio da subsidiariedade do Direito Penal que visa limitar o poder punitivo do Estado.

Nesse ínterim, de acordo com os estudos de Borges (2018), denominado "O que é encarceramento em massa?", permite-nos pensar acerca da ordem do encarceramento marcada pela segregação, opressão e invisibilidade dos cidadãos. Outrossim, encoraja-nos a pensar o porquê que essa cultura judicializada e criminalizadora não atinge a todos de mesma forma, mas sim, preferencial e majoritariamente, a determinados grupos sociais.

O sistema de justiça criminal tem profunda conexão com o racismo, sendo o funcionamento de suas engrenagens mais do que perpassados por esta estrutura de opressão, mas o aparato reordenado para garantir a manutenção do racismo e, portanto, das desigualdades baseadas na hierarquização racial [...] Tanto o cárcere quanto o pós-encarceramento significam a morte social destes indivíduos negros que, dificilmente, por conta do estigma social, terão restituído o seu status [...] de cidadania ou possibilidade de alcançá-la (BORGES, 2018, p. 16-17)

À vista disso, a população carcerária é notadamente uma fração social que não está em harmonia com o Estado neoliberal, ou seja, não combinam com o Estado em ascensão que busca uma boa imagem internacional. Com isso, de forma estratégica, o Estado maquia os problemas sociais se utilizando do encarceramento em massa, dando uma resposta oficial a população aterrorizada por uma mídia sensacionalista. Desse modo, na perspectiva estatal, é mais fácil aumentar a força do Estado penal, fazendo com que esses cidadãos se calem dentro de estabelecimentos prisionais, já que pelo contrário, demandaria mais gastos em serviços públicos e programas sociais. Para enfatizar esse pensamento, importa mencionar as palavras de Becky Pettit (2012, apud De Giorgi, 2017, p. 18), ao falar do sistema carcerário americano.

Presidiários e ex-presidiários são categórica e sistematicamente excluídos dos esforços de coleta de dados que retratam as políticas sociais e as pesquisas das ciências sociais americanas. Sua exclusão obscurece nosso entendimento da condição econômica, política e social americana. 
A partir desse fragmento, nota-se que o encarceramento em massa é o reflexo da negligência institucional que existe em relação aos apenados, ao passo que os Estados camuflam as desigualdades sociais para que tenham índices melhores do que constam na realidade.

\section{PERFILSOCIAL DO ENCARCERADO: ASELETIVIDADE DA LEI DE DROGAS}

A análise dos tópicos da pesquisa voltados a identificar o perfil social dos apenados, quais sejam etnia, gênero, idade, estado civil, existência de filhos, profissão, local de residência antes da prisão e grau de escolaridade, apresentou um padrão majoritário recorrente o qual demonstra a propensão da lei antidrogas em punir uma específica parcela da sociedade.

A princípio, na sua maioria, os apenados eram solteiros, com 38 (trinta e oito) ocorrências e, logo em seguida, predominou os relacionamentos sem vínculo formal, com 32 (trinta e dois) casos. Por fim, somente 4 (quatro) eram casados e 1 (um) era divorciado. Ademais, 30 (trinta) deles não possuíam filhos, à medida que 16 (dezesseis), sim. Esse quadro apresenta uma defasagem das relações sociais desses indivíduos, a qual se deve, principalmente, pela prematuridade no ingresso ao tráfico de drogas. De acordo com Silva (2001, p. 144):

Os indivíduos que estão ingressando no crime são cada vez mais jovens, motivo pelo qual muitos chegam à maioridade com trajetórias criminosas caracterizados por experiências múltiplas em instituições carcerárias, o que os impossibilitaria de contrair matrimônio e constituir família.

O fenômeno das facções criminosas é um dos responsáveis pelo ingresso precoce dos indivíduos à delinquência. A sensação de poder, ligada a masculinidade e ao consumo, além do simbolismo resultante da noção de pertencimento a um grupo, são os principais atrativos aos menores, que se encontram, notadamente, em vulnerabilidade social (NOGUEIRA, 2018).

Nesse sentido, do contingente pesquisado, dividiu-se por faixa etária, encontrando-se o seguinte quadro: 19 (dezenove) foram condenados entre 18 e 21 anos, 15 (quinze) entre 22 e 25 anos e 20 (vinte) entre 26 e 30 anos. Assim, eram jovens 54 (cinquenta e quatro) apenados à data do crime ${ }^{2}$. Ademais, foram 13 (treze) condenados entre 31 e 35 anos, 8 (oito) entre 36 e 40 anos e 7 (sete) com mais de 40 anos.

Vale ressaltar que, embora seja um tópico atinente a seara processual, a proporção de 55 (cinquenta e cinco) apenados não-reincidentes contra 22 (vinte e dois) reincidentes, demonstrados na pesquisa, evidencia o encarceramento de jovens em massa, pois, como visto, a faixa etária entre 18 e 29 anos demarca a maior ocorrência do início da prática de crimes de drogas na maioridade e, muitas vezes, ocasiona a primeira condenação.

Diante disso, surge o questionamento sobre quais as circunstâncias que levam esses apenados a

\footnotetext{
${ }^{2}$ Conforme classificação do artigo $1^{\circ}, \S 1^{\circ}$, da Lei n ${ }^{\circ} 12.852 / 2013$ (Estatuto da Juventude).
} 
serem atraídos pelas recompensas da atividade criminosa. Para elucidar tais questões, é necessário observar os dados atinentes ao nível de instrução e a situação econômica.

Quanto ao grau de instrução, demonstrou-se uma baixa escolaridade, visto que 29 (vinte e nove) apenados possuíam o ensino fundamental, 6 (seis) o ensino médio e 3 (três) não tinham escolaridade, além de que nenhum indivíduo possuía ensino superior. Essa defasagem educacional conduz os indivíduos a se estabelecerem à margem da sociedade. Segundo Wacquant (2003, p. 34) “A grande maioria dos internos dos cárceres municipais provem seguramente das categorias dos “working poor”, esta fração da classe operária que não consegue subtrair-se da miséria, embora trabalhe".

A constatação do parágrafo anterior reforça-se à medida que a análise dos dados demonstrou que 17 (dezessete) apenados eram desempregados, ao passo que 44 (quarenta e quatro) trabalhavam ao tempo do delito. No entanto, dentre os 19 (dezenove) tipos de profissões catalogadas, 14 (catorze) dessas atividades laborais estavam presentes no Cadastro Geral de Empregados e Desempregados - CAGED, constante ao âmbito do Município de Mossoró/RN, local de 69,31\% dos casos, quais sejam gesseiro, agricultor, pescador, empregado doméstico, açougueiro, operador de máquinas, lavador de Veículos, jardineiro, pedreiro, borracheiro, polidor, soldador, marceneiro e mecânico de automóveis, o qual se constatou que os empregados em questão são de baixa remuneração, uma vez que essas profissões foram limitadas a uma renda média mensal de valores entre $\mathrm{R} \$ 1.382,75$ (mil trezentos e oitenta e dois reais e setenta e cinco centavos) pago a um soldador e R \$ 996,60 (novecentos e noventa e seis reais e sessenta centavos) a um gesseiro (BRASIL,2019), gravitando bem próximo em torno da linha nacional de pobreza estabelecida de acordo com a orientação do Banco Mundial ao Brasil (IBGE, 2019), que tem como patamar atual uma renda mensal per capita de R\$ 904,20 (novecentos e quatro reais e vinte centavos) ${ }^{3}$.

A fragilidade econômica dos apenados torna-se mais evidente ao olharmos para as localidades das suas residências. O valor médio do metro quadrado em 20 (vinte) dos 22 (vinte e dois) bairros de Mossoró encontrados na pesquisa, quais sejam Santo Antônio, Abolição IV, Belo Horizonte, Dom Jaime Câmara, Barrocas, Bom Jardim, Redenção I, Santa Delmira, Alto da Conceição, Alto do Sumaré, Três Vinténs, Nova Mossoró, Paredões, Aeroporto II, Costa e Silva, Aeroporto I, Rincão, Ilha de Santa Luzia, Planalto 13 de Maio e Boa Vista, são de 1,33 a 8,52 vezes mais baratos em comparação ao do bairro Nova Bethânia, considerado um de maior valorização imobiliária da cidade ${ }^{4}$. Com isso, quanto menor a valorização dessas áreas, maior a presença de pessoas de baixa renda, notoriamente, colocadas à margem das ações estatais.

Além das condições socioeconômicas que condicionam um determinado grupo de indivíduos a cometer crimes relacionados a drogas, a lei de entorpecentes ainda possui preferências biológicas, referente à

\footnotetext{
${ }^{3}$ Taxa de conversão da paridade de poder de compra para consumo privado. US\$ 1,00 PPC para R\$ 5,48, em 29/06/2020. A orientação dada ao Brasil é de US\$ 5,5 PPC por dia, o que convertido para o Real, ao longo de 1 mês (30 dias), gera a quantia de R\$ 904,20.

${ }^{4}$ De acordo com as informações obtidas através da Prefeitura Municipal de Mossoró, por meio do Departamento de Receitas Imobiliárias da Secretaria da Fazenda, constante ao valor médio do metro quadrado por bairros, que consta do período de 01/06/2018 a 01/06/2020.
} 
etnia e ao gênero, para ser alvo de seus mandamentos.

Em relação à etnia, a pesquisa contabilizou 16 (dezesseis) apenados negros, 28 (vinte e oito) pardos e 11 (onze) brancos. Com isso, dentre os identificados, para cada 1 (um) apenado branco, há 4 (quatro) do grupo formado por negros e pardos. Essa proporção representa a discrepância racial existente no Brasil, marcada por um longo período de escravidão que resultou em um cenário atual de forte desigualdade social (BATISTA, 2003).

Um Estado Penal, por sua vez, cria uma seletividade em face das populações menos favorecidas e sujeitas a determinados tipos de crimes que ocorrem em virtude desta condição (CARDOSO, MONTEIRO, 2013), como o tráfico de entorpecentes e a sua promessa de rentabilidade. Por consequência disso, verifica-se a presença de uma biopolítica criminal que estigmatiza negros e pardos com o argumento racista de que estes são propensos à prática de atos criminosos (LEMOS, AQUIMES, et al., 2017).

No que pese ao gênero, a pesquisa demonstrou que o tráfico de drogas se mostra um crime extremamente masculino, sendo constatado 58 (cinquenta e oito) homens contra 19 (dezenove) mulheres. Ademais, no contexto nacional, esse quadro se reforça à medida que, de acordo com o Levantamento Nacional de Informações Penitenciárias - INFOPEN, a quantidade de incidências penais por crimes de drogas (condenados ou que aguardam julgamento) era de 156.749 (cento e cinquenta e seis mil e setecentos e quarenta e nove), sendo 140.798 (cento e quarenta mil setecentos e noventa e oito) cometidos por homens e 15.951 (quinze mil novecentos e cinquenta e um) por mulheres, além disso, o estudo ainda demonstrou que o crime de tráfico de drogas figurava como a $2^{\circ}$ maior causa de encarceramento de homens no Brasil, com 29,26\%, ficando atrás apenas do roubo, com 31,88\% (BRASIL,2017).

Quanto às mulheres, chama atenção o fato de que, segundo o Relatório Temático Sobre Mulheres Privadas de Liberdade - INFOPEN Mulheres, o crime de tráfico de drogas era o responsável pela maior parte das prisões no âmbito nacional, contabilizando um total de 59,98\% dos casos, ademais, especificamente no Estado do Rio Grande do Norte, o crime de tráfico de entorpecentes representava $80,4 \%$ das causas que levavam mulheres a serem privadas de liberdade(BRASIL,2017).

A participação feminina no tráfico de drogas se deve, também, pela influência de companheiros e familiares, mas, principalmente, pela feminização da pobreza, fenômeno no qual o desemprego e as dificuldades financeiras têm afetado as mulheres e norteado suas ações (CORTINA, 2015), sendo esta realidade socioeconômica o ponto de congruência entre homens e mulheres.

Por fim, apesar do INFOPEN ser uma pesquisa do sistema carcerário nacional, o resultado deste se assemelha fielmente ao perfil dos encarcerados, especificamente condenados por crimes de drogas, na Comarca de Mossoró, ao concluir que "a maior parte dos condenados é composta por jovens, pretos, pardos e com baixa escolaridade" (BRASIL, 2017, p. 68).

\section{ANÁLISE DAS RELAÇÕES PROCESSUAIS QUE RESULTARAM EM CONDENAÇÕES POR CRIMES ELENCADOS NA LEI N. ${ }^{\circ}$ 11.343/2006 E AATUAÇÃO DA POLÍTICAANTIDROGAS NA}




\section{COMARCADE MOSSORÓ}

Publicada em 2006, a Lei n. ${ }^{\circ}$ 11.343/2006 pretende prescrever medidas para prevenção do uso indevido de entorpecentes, bem como implementar a atenção e reinserção social de usuários e dependentes de drogas, desse modo, estabelece normas para repressão à produção não autorizada e ao tráfico ilícito de drogas e define crimes ${ }^{5}$. Assim, para alcançar os objetivos propostos neste trabalho, realizou-se uma análise acurada das sentenças, e se verificou a incidência de tipos incriminadores específicos, dentro da análise dos 88 (oitenta e oito) processos de conhecimento.

Pois bem, o art. 28 da mencionada lei que trata do porte de drogas para consumo pessoal, aplicou-se em apenas 4 (quatro) indivíduos. Já o art. 33, caput, que regula o tráfico de drogas, foi, ainda, dividido nas modalidades presentes em seu parágrafo $\S 1^{\circ}$, III e $\S 4^{\circ}$, respectivamente, sobre a utilização de local para tráfico e da causa de diminuição de pena em virtude do tráfico privilegiado. Dito isso, pelo caput do art. 33 da Lei de Drogas, foram 56 pessoas condenadas, seguido de 1 (uma pessoa) pelo $\S 1^{\circ}$, III e de 20 (vinte) pela minorante prevista no $\S 44^{\circ}$, o qual se nota uma certa resistência acerca da aplicação desta em virtude da baixa frequência. Outrossim, o tipo penalizador de associação para o tráfico (art. 35, caput), incriminou 9 (nove) pessoas, já o art. 36, que pune o financiamento de práticas ligadas às drogas, teve apenas 1 (um) condenado.

Para além disso, importa-se mencionar que outros crimes foram cometidos em concurso com os crimes relacionados a drogas. Nesse sentido, houve a presença da prática de crimes contra o patrimônio em 3 (três) condenações; crimes dolosos contra vida em 1 (uma) condenação; crimes contra a administração pública em 2 (duas) condenações; crimes contra o estatuto do desarmamento em 7 (sete) condenações e em crimes contra o meio ambiente, 1 (uma) condenação.

Diante dos dados, é notória a maior incidência de condenações com base no art. 33, caput, da lei de drogas. Todavia, pode-se questionar a proporcionalidade dessas prisões, uma vez que o tipo não esboça a quantidade de drogas para que seja caracterizado o uso ou o tráfico, além de não diferenciar o pequeno do grande traficante. A lei, claramente, não oferece critérios legais para essa distinção, já que a normativa jurídica ignora o real fenômeno do tráfico de drogas. Nesse sentido, visualiza-se o caput do art. 33, como sendo um tipo aberto, amplo, em vez de ser específico e limitador da intervenção penal, uma vez que não há critérios objetivos de diferenciação, a não ser a previsão do $\S 4^{\circ}$, que ainda assim, foi pouco aplicado.

Quanto ao tipo da defesa técnica nos processos, diante do conjunto de 88 (oitenta e oito) processos de conhecimento, 6 (seis) dos acusados tiveram defesas dativas, ao passo que 28 (vinte e oito) tiveram defesas públicas e 54 (cinquenta e quatro), constituídas. Já à luz dos processos de execução, dos quais foram analisados 77 (setenta e sete), 26 (vinte e seis) apenados tiveram defesas públicas, 32 (trinta e duas) foramconstituídas e não houve defesas dativas. Assim, nota-se que na tramitação dos processos de conhecimento predominou a defesa constituída, à medida que na fase de execução os números se

\footnotetext{
${ }^{5}$ Art. 1. ${ }^{\circ}$ da lei 11.343/2006 (Lei de Drogas).
} 
equilibraram, o que aponta para uma dificuldade financeira dos apenados na manutenção de uma defesa patrocinada as suas expensas.

Em relação à quantidade de penas aplicadas, o tempo de pena entre 5 (cinco) e 6 (seis) anos foi a de maior incidência, seguido das penas maiores que 6 (seis) e menores que 7 (sete) anos, e das maiores que 1 (um) e menores que 2 (dois) anos, ambas com 11 (onze) condenados. Já as penas restritivas de direitos apareceram 5 (cinco) vezes. Com isso, os tipos de regimes variaram, como é observado no gráfico abaixo:

Anexo A - Representação gráfica das penas referente aos tipos criminais da Lei $n^{\circ}$ 11.343/2006.

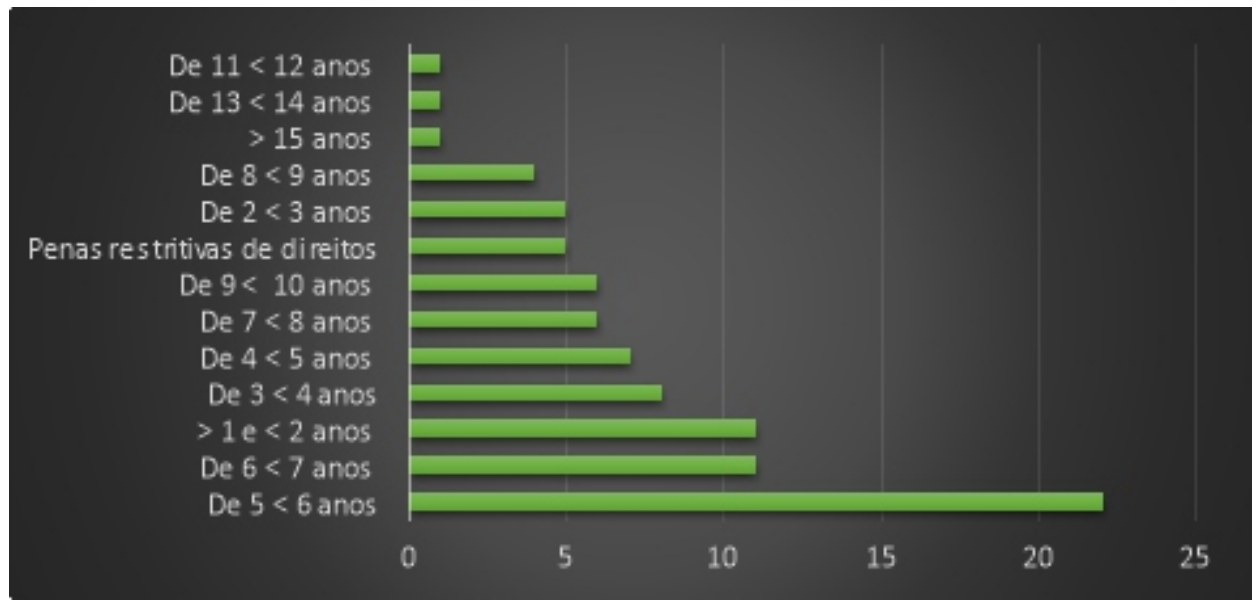

FONTE: autoria própria.

Notou-se também a maior ocorrência do regime fechado, com 33 (trinta e três) pessoas condenadas, seguido do semiaberto com 28 (vinte e oito), e o aberto com 17 (dezessete) condenados. O presente dado demonstra, claramente, a questão do encarceramento em massa que ocorre no sistema penitenciário brasileiro e gera o fortalecimento do populismo punitivo. Nas palavras de BORGES (2018, p. 30), “a punição já foi naturalizada no imaginário social".

Nesse ínterim, vale mencionar que o populismo punitivista é uma visão hodierna intensamente difundida pela cultura do medo, o qual enxerga o delinquente como inimigo e parte não integrante da sociedade que merece ser segregado e estocado dentro das penitenciárias.

Todo populismo surge dentro da história como um método de doutrinar as massas. Com o populismo penal não é diferente, pois se mostra a partir do consenso popular de legitimar as ações do Estado, o qual atua através de suas instituições, tal como pela atividade da Polícia, que buscam conter o progresso criminoso.

O populismo penal ou punitivo atua no sentido de acreditar que todo o problema dessa realidade criminógena contemporânea será resolvida com mais punição e prisões. Destarte, reforçando a ideia, André Gaio diz que "o populismo penal alimentaria a raiva e o ressentimento, reconfigurando o poder para punir, elegendo a prisão como a ferramenta central da nova política penal” (GAIO, p. 22, 2011).

Para Pratt (2007), o populismo punitivo é a locução que expressa o descontentamento popular generalizado diante do sistema de justiça criminal que se traduz através de uma série de discursos que 
convergem ao significado de impunidade e violência que cercam a sociedade contemporânea. Todavia, não será por esse motivo, que as penas devem ser usadas como meio de solucionar todos os conflitos sociais existentes. Nem mesmo devem ser aplicadas embasadas no sentimento de comoção social, como se é feito, já que o Estado, através do protagonismo jurisdicional, estabelece como respostas as prisões ao invés de aplicar as "onerosa" políticas sociais. Nesse comento, Pavarini e Giamberardino inferem que:

[...] a referência a partir da qual determinar a pena merecida é o sendo comum das pessoas, ou seja, quer-se realizar a dosimetria da pena 'em concreto' como sendo aquela considerada como justa pela opinião pública. A referência ao conceito de merecimento não é mais um componente da perspectiva de limitação do poder discricionário na aplicação da pena, e sim de sua vinculação ao alarme social. (PAVARINI; GIAMBERARDINO, 2018, p. 138 e 139).

Ademais, vivencia-se um momento em que é necessário se preocupar com a disseminação do pânico moral, pois, esse cenário, além de contribuir para a aderência ao populismo penal, concorre com atitudes subjetivas e discricionárias por parte do Estado.

Em relação ao tempo de tramitação dos processos de conhecimento, registrou-se que dos 88 (oitenta e oito) analisados, 28 deles duraram menos que 1 (um) ano. Nesse ponto, considera-se algo positivo na prestação jurisdicional da Comarca, uma vez que os números mostram a efetivação do direito a razoável duração do processo. Todavia, em menos de 5 processos de conhecimento o tempo foi de mais de 6 e menor que 7 anos, como é observado no gráfico abaixo:

Anexo B - Representação gráfica do tempo de duração dos processos em fase de conhecimento.

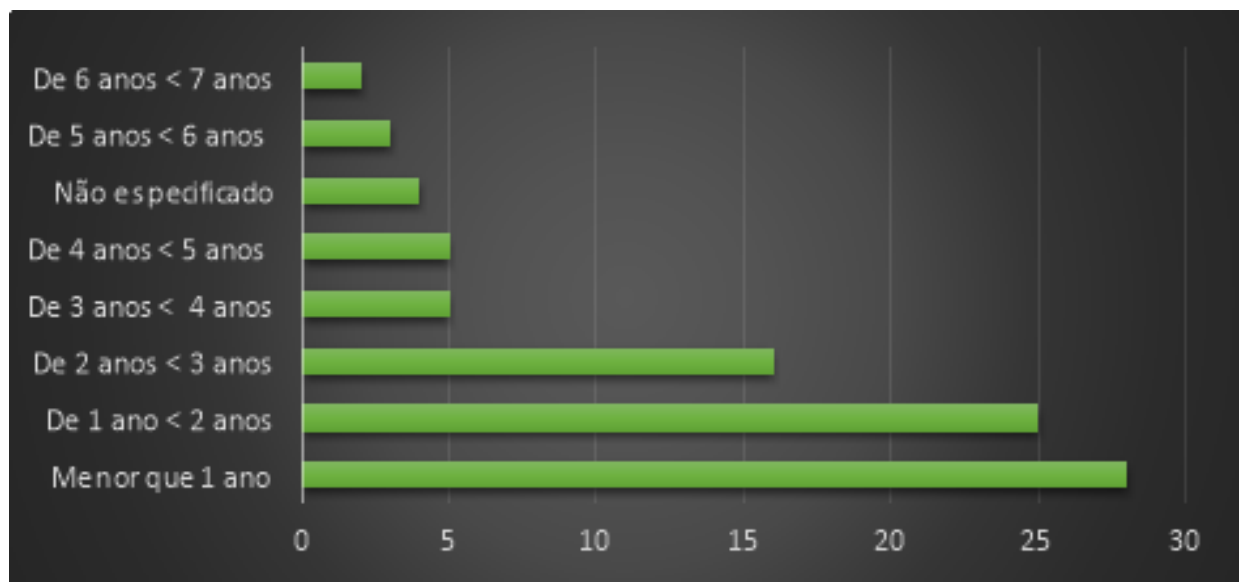

FONTE: autoria própria.

Noutro giro, dentre os fatores para a aplicação da pena, é considerado a quantidade de droga apreendida no momento do flagrante. Com efeito, as drogas apreendidas resumiram-se a maconha, crack e cocaína, presentes em 54 (cinquenta e quatro), 45 (quarenta e cinco) e 18 (dezoito) ocorrências, respectivamente. 
Nos casos em que a maconha esteve presente, em 33 (trinta e três) destes foram apreendidas, no máximo, 100 (cem) gramas ou 100 (cem) trouxinhas, já na perspectiva do crack, foi encontrada a mesma quantia em 31 (trinta e um) incidentes, ao passo que o quadro se repetiu em 11 (onze) oportunidades com a cocaína, assim, essa proporção esteve presente em $70 \%$ dos flagrantes.

O elevado índice de prisões por baixas quantidades de drogas é um reflexo da política antidroga, a qual não foca sua atenção pública às organizações criminosas, aprisionando, na maioria das vezes, apenas pequenos varejistas (WACQUANT, 2003). Este quadro se coaduna ao pensamento de Olavo Hamilton (ANDRADE, 2015), quando afirma que a maioria dos encarcerados são pequenos traficantes sem vínculo direto com atividades violentas. Estes fatos justificam a proporção, encontrada na pesquisa, de 6 (seis) apenados envolvidos em organizações criminosas contra 67 (sessenta e sete) que não possuíam envolvimento. À vista disso, observa-se uma inefetividade da referida política, uma vez que os maiores responsáveis pelos danos sociais vinculados as drogas são os menos afetados, enquanto que o Estado gasta para punir pequenos varejistas.

\section{CONSIDERAÇÕES FINAIS}

A atual política de drogas encarcera na Comarca de Mossoró - RN, em sua maioria, as pessoas de baixo grau de ensino, pois este fator atua como vetor socioeconômico e os condiciona ao desemprego ou a uma posição marginal no mercado de trabalho o que resulta em baixas condições econômicas e favorece o aliciamento pelo tráfico. Além disso, constatamos que estes indivíduos, na sua maior parte, moram em bairros periféricos e são negros ou pardos, jovens e não possuem estrutura familiar bem definida. Diante disso, concluímos que há um direcionamento sanitarista a setores vulneráveis da população, dessa forma, a legislação antidroga provoca uma verdadeira eugenia social e retira de circulação os indesejados sociais, assim, verifica-se a presença do encarceramento em massa como forma de controle social.

Ademais, a política antidrogas mostra-se inócua, pois, encarcera, principalmente, pequenos traficantes, cujos danos à sociedade, bem como os impactos das suas prisões na oferta e no consumo de drogas são insignificantes em relação aos do crime organizado, fato que demonstra o desperdício de recursos públicos. Dessa forma, a lei de drogas se distancia da principiologia constitucional, pois converte o cidadão marginalizado em marginal e apresenta como única presença estatal em sua vivência o sistema punitivo, assim o exclui das demais políticas públicas básicas e gera mais problemas do que resolve.

Por fim, constata-se que a lei de drogas é um produto do Estado penal brasileiro, o qual, notadamente, tende a punir os pobres e, por isso, independente da realidade em que for aplicada, a referida lei mostra-se tender a produzir os mesmos resultados seletivos em detrimento dos menos favorecidos, ainda que em contextos socioeconômicos e culturais específicos, como os das regiões que compreendem a Comarca de Mossoró. O resultado da pesquisa é, portanto, um reflexo do sistema carcerário nacional, apesar deste englobar um conjunto de regiões e tipos penais distintos, o que reforça, assim, o caráter do Direito penal no 
Brasil de produzir, em qualquer circunstância, o mesmo resultado.

\section{REFERÊNCIAS BIBLIOGRÁFICAS:}

ANDRADE, Olavo Hamilton Ayres Freire de. Princípio da proporcionalidade e guerra contra as drogas. 2. ed. Natal-RN: OWL, 2015.

BATISTA. Vera Malaguti. Difíceis Ganhos Fáceis. Drogas e Juventude Pobre no Rio de Janeiro. 2. ed. Rio de Janeiro: Revan, 2003.

BORGES, Juliana. O que é: encarceramento em massa?. Belo Horizonte, Minas Gerais. Letramento: Justificanto, 2018.

BRASIL. Ministério da Justiça. Departamento Penitenciário Nacional. Levantamento Nacional de Informações penitenciárias. INFOPEN, junho de 2017 . <Disponível em http://antigo.depen.gov.br/DEPEN/depen/sisdepen/infopen/relatorios-sinteticos/infopen-jun-2017-rev12072019-0721.pdf> Acesso em: 03 out. 2020.

BRASIL. Ministério da Justiça. Departamento Penitenciário Nacional. Relatório Temático Sobre Mulheres Privadas de Liberdade. INFOPEN Mulheres, junho de 2017. <Disponível em h t t p : / / a n t igo.depen.gov.br/DEPEN/depen/sisdepen/infopenmulheres/copy_of_Infopenmulheresjunho2017.pdf>Acesso em: 05 out. 2020.

BRASIL. Dados sobre população carcerária do Brasil. INFOPEN, 2019 <Disponível em: https://www.gov.br/pt-br/notícias/justiças-e-segurança/2020/02/dados-sobre-população-carceraria-dobrasil-são-divulgados>Acesso em: 8 set. 2020.

BRASIL. Cadastro Geral de Empregados e Desempregados. CAGED. Perfil do município. Ministério da Economia, Secretaria Especial de Previdência e Trabalho, 2019. <Disponível em: http://pdet.mte.gov.br/perfil-do-municipio>Acesso em: 03 jul. 2020.

CORTINA, Monica Ovinski de Camargo. Mulheres e tráfico de drogas: aprisionamento e criminologia feminista. Rev. Estud. Fem. , Florianópolis, v. 23, n. 3, pág.761-778, dezembro de 2015. <Disponível em http://www.scielo.br/scielo.php?script=sci_arttext\&pid=S0104026X2015000300761\&lng=en\&nrm=iso $>$. Acesso em: 07 set 2020.

DA SILVA, Raissa Zago Leite. Labelling Approach: o etiquetamento social relacionado à seletividade do sistema penal e ao ciclo da criminalização. Revista Liberdades. <Dsponível em:http://www.revistaliberdades.org.br/site/outrasEdicoes/outrasEdicoesExibir.php?rcon_id=225> Acesso em: 08 set. 2020.

DE GIORGI, Alessandro De Giorgi. Cinco teses sobre o encarceramento em massa [recurso eletrônico] / 
Alessandro De Giorgi; tradução Leandro Ayres França. - Porto Alegre : Canal Ciências Criminais, 2017, p. 18.

GAIO, André M. O populismo punitivo no Brasil. CSOnline-Revista eletrônica de Ciências Sociais, n. 12, 11 jul. 2011.

IBGE. Síntese de indicadores sociais. Uma análise das condições de vida da população brasileira 2019. $<$ Disponível em: https://biblioteca.ibge.gov.br/visualizacao/livros/liv101678.pdf>Acesso em: 30 jun. 2020. LAKATOS, Eva Maria; MARCONI, Marina de Andrade. Fundamentos de metodologia científica. 5. ed. São Paulo: Atlas, 2003.

LAKATOS, Eva Maria; MARCONI, Marina de Andrade. Fundamentos de metodologia científica. 6. ed. São Paulo: Atlas, 2005.

LEMOS, Flávia Cristina Silveira et al. O extermínio de jovens negros pobres no Brasil: práticas biopolíticas em questão. Revista Pesquisas e Práticas Psicossociais. v. 12, n. 1 (2017). p. 164-174.

MONTEIRO, Felipe Matos; CARDOSO, Gabriela Ribeiro. A seletividade do sistema prisional brasileiro e o p e r fi l d a p o p u l a çã o c a r c e r ár i a 2013 . C D i s p o nín e 1 e m : http://depen.gov.br/DEPEN/depen/espen/Aseletividadedosistemaprisionalbrasileiro.pdf> Acesso em: 30 jun. 2020.

NOGUEIRA, J, A. Enquanto o Estado nega, as facções criminosas abraçam: uma abordagem a partir dos relatos dos adolescentes internados no Centro Educacional de Mossoró (CEDUC). Monografia (Graduação em Bacharel em Direito). Faculdade de Direito - FAD, Universidade do Estado do Rio Grande do Norte UERN, Mossoró RN, p. 149, 2018.

PAVARINI, Massimo. GIAMBERARDINO, André. Curso de Penalogia e execução penal. Florianópolis : Ed. Tirant lo BlancH, 2018.

PRATT, John. Penal Populism. New York: Routledge, 2007.

SILVA, Rubens Alexandre da. Prisões e Presidiários: o tema e a produção teórica. Caderno de Campo.

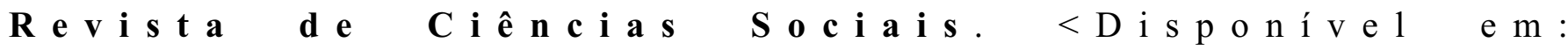
https://periodicos.fclar.unesp.br/cadernos/article/view/10381/6781>. Acesso em: 08 set. 2020.

TEIXEIRA, Elizabeth. As três metodologias: acadêmica, da ciência e da pesquisa. 7. ed. Petrópolis: Vozes, 2010 .

WACQUANT, Loic. Punir os pobres: a nova gestão da miséria nos Estados Unidos. Instituto Carioca de Criminologia. Coleção Pensamento Criminológico. Volume: 6. Rio de Janeiro: Freitas Bastos, 2003.

ZAFFARONI, Eugenio Raúl. Em busca das penas perdidas: a perda de legitimidade do sistema penal. Rio de Janeiro: Revan, 1991. 